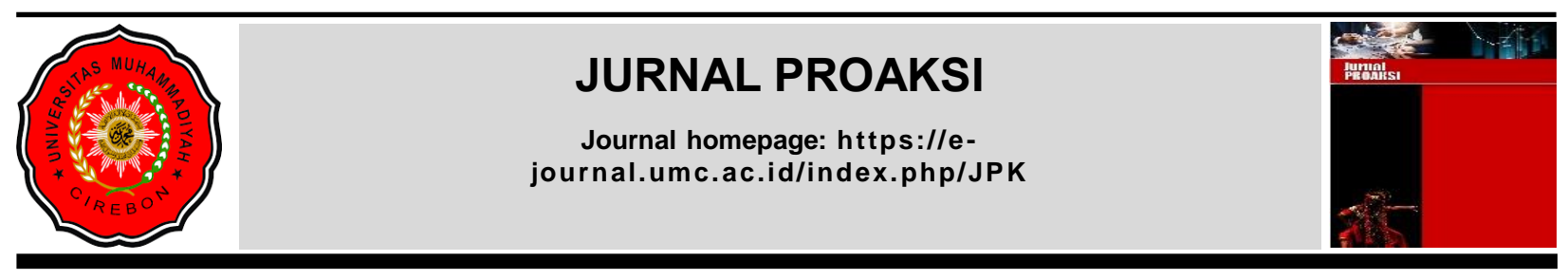

\title{
CAPITAL STRUCTURE, COMPANY SIZE DAN PROFITABILITY TERHADAP NILAI PERUSAHAAN
}

\author{
Mustakin ${ }^{1}$ \\ Salamatun Asakdiyah ${ }^{2}$ \\ Taufik Hidayat ${ }^{3}$ \\ ${ }^{1}$ Fakultas Ekonomi dan Bisnis, Universitas Ahmad Dahlan \\ Email : Takinmus77@gmail.com \\ ${ }^{2}$ Fakultas Ekonomi dan Bisnis, Universitas Ahmad Dahlan \\ Email : salamatun_2009@yahoo.com \\ ${ }^{3}$ Fakultas Ekonomi dan Bisnis, Universitas Ahmad Dahlan \\ Email : thidayat60@gmail.com
}

\begin{abstract}
Abstrak
Perusahaan yang sudah go public pasti memunculkan nilai perusahaan yang maksimal untuk menarik perhatian dari investor. Banyak faktor yang mampu memaksimalkan nilai perusahaan terutama dalam peningkatan modal, size dan tingkat keuntungan. Penelitian ini memiliki tujuan untuk menjelaskan tingkat keterkaitan capital structure, size, dan profitabily dengan nilai perusahaan studi kasus pada perusahaan otomotif yang ada dalam list BEI. Populasi yang di ambil merupakan perusahaanyang bergerak di bidang otomotif yang masuk dalam daftar BEI periode tahun 2015-2018. Penelitian menggunakan variabel bebas DER, Size, dan ROA. Variabel terikat yang dipakai adalah Price Book Value. Sampel yang diambil adalah 14 perusahaan yang memenuhi kriteria yang sudah ditentukan. Data diperoleh dengan teknik dokumentasi dan teknik analisis data menggunakan analisis regresi data panel. Pengujian memberikan hasil bahwa hipotesis pertama struktur modal tidak memiliki pengaruh signifikan terhadap nilai perusahaan otomotif, hipotesis kedua ukuran perusahaan tidak memiliki pengaruh signifikan terhadap nilai perusahaan otomotif, hipotesis ketiga profitibilitas tidak memiliki pengaruh signifikan terhadap nilai perusahaan otomotif.
\end{abstract}

Keywords: Nilai Perusahaan, Struktur Modal, Ukuran perusahaan, dan Profitabilitas

\section{PENDAHULUAN}

Perusahaan secara umum mempunyai maksud untuk jangka waktu panjang antara lain untuk menaikkkan nilai sebuah perusahaan, peningkatan kesejahteraan shareholder dan tingkat laba yang maksimal. Tujuan tersebut merupakan hal yang wajib dilakukan oleh perusahaan Go Public untuk memberikan gambaran yang menarik bagi para Investor untuk ikut terlibat dalam pengembangan perusahaan (Suwardika dan Mustanda, 2017). Indonesia merupakan salah satu pangsa pasar otomotif terbesar di dunia dengan tingkat konsumsi kendaraan yang cukup tinggi. Tidak heran kemudian industri ototmotif menjadi salah satu penggerak utama perekonomian Indonesia. Otomotif memiliki bussiness chain yang mencakup industri manufaktur komponen, manufaktur yang berhubungan dengan kendaraan itu sendiri, distribution chain dan service dari bengkel resmi atau umum, serta penjualan spare part. Begitu ketatnya persaingan dalam industri otomotif maka perusahaan yang sudah go public berusaha mencapai competitive advantage yang unik dan tidak dipunyai oleh perusahaan kompetitor, dengan demikian diharapakn perusahaan memiliki nilai yang semakin tinggi dalam persaingan sehingga menjadi magnet bagi para investor untuk menanamkan modalnya. 
Perusahan memiliki nilai yang ditunjukkan dengan harga saham suatu perusahaan, namun ada juga untuk mengukur tingginya nilai perusahaan melalui berbagai cara antara lain price to book value. Brigham and Houston (2011) menjelaskan price to book value (PBV) adalah rasio keuangan yang membandingkan antara harga saham dengan nilai buku per lembar saham. Jika nilai PBV yang semakin tinggi maka semakin besar pula tingkat kemakmuran dari pemegang saham, sehingga perusahaan dikatakan telah mencapai salah satu tujuannya. Menurut Jogiyanto (2016) mengatakan bahwa untuk menganalisis nilai perusahaan bisa menggunakan analisis fundamental yang berasal dari annual report perusahaan baik dari aspek modal, ukuran perusahaan dan profitabilitas.

Size (ukuran perusahaan) adalah kecil atau besarnya perusahaan yang dapat dilihat dari besarnya modal, penjualan dan total harta perusahaan. Semakin besar jumlah harta yang dimiliki perusahaan maka bisa digambarkan perusahaan sudah dalam taraf dewasa. Tahap kedewasaan perusahaan tercapai ketika memiliki arus kas yang positif dan mampu memperkirakan keuntungan dalam periode yang panjang. Kecil besarnya jumlah harta atau modal yang dimiliki oleh perusahaan adalah cerminan dari ukuran perusahaan. Size yang semakin tinggi akan berkorelasi dengan keputusan pendanaan yang akan diputuskan oleh perusahaan untuk meningkatkan nilai perusahaan (Suwardika dan Mustanda, 2017).

Manager keuangan akan menghadapi dilema terkait dengan keputusan operasional perusahaan, hal ini terkait dengan penentuan struktur modal. Struktur modal disini adalah keputusan dalam bidang financial berkaitan dengan struktur hutang, preferen stock dan common stock yang secara umum dipakai oleh perusahaan, hal tersebut dipakai sebagai bentuk alternatif pembiayaan perusahaan melalui dana eksternal. Struktur modal merupakan penggunaan hutang jangka panjang terhadap modal sendiri. Book Value menggambarkan stock value di pandang dari pembukuan emiten, market value adalah nilai saham berdasarkan book value di pasar saham dan intrinsic value dari nilai saham yang sebenarnya. Penentuan model pendekatan intrinsic value adalah price book value. PBV adalah rasio penilaian yang menerapkan pengukuran berdasarkan tingkat manajerial skill yang menghasilkan nilai pasar terhadap biaya investasi yang sudah dikeluarkan melalui perbandingan market value dari saham kepada book value (Kasmir, 2009:116). Tinggi rendahnya PBV Ratio bergantung pada penciptaan nilai bagi pemegang saham dan memiliki dampak bagi peningkatan atau penurunan nilai suatu perusahaan.

\section{KAJIAN PUSTAKA Nilai Perusahaan}

PBV teridentifikasi dari value dari capital yang dibagi dengan total stock yang dimiliki. Dengan kata lain book value merupakan book value per share (BVPS). Ekuitas didefinisikan sebagai selisih dari total aset dikurangi dengan liability. Kemudian dalam pandangan teori menyatakan bahwa value bisa diperoleh oleh pemilik saham jika perusahaan mengalami likuidasi. Sehingga book value memperlihatkan timbal balik dari hasil investasi (Manoppo dan Valdi, 2016).

\section{Capital Structure}

\section{PBV = Harga saham perusahaan BV perusahaan}

DER merupakan rasio hutang untuk mengukur tingkat pinjaman dari keuangan perusahaan dan dikalkulasi berdasarkan perbandingan jumlah total liabilitas dibanding dengan jumlah total ekuitas. DER mengindikasikan seberapa besar hutang sebuah perusahaan yang digunakan untuk menjalankan operasionalnya dibandingkan dengan nilai ekuitas yang dimilikinya (Manoppo dan Valdi, 2016).

\section{Debt to Equity Ratio $=\frac{\text { Total Hutang }}{\text { Equity (Ekuitas) }}$}

Size

Size memiliki 3 (tiga) komponen, yaitu large firm, medium firm and small firm. Periode kedewasaan perusahaan dapat ditetapkan melalui total aktiva, semakin besar total aktivamenggambarkan perusahaan memiliki prospek yang baik dalam jangka waktu yang panjang.

Size = Logaritma Natural dari Total Aset 


\section{Profitability}

Profitablitas atau kemampuan memperoleh laba adalah suatu ukuran dalam persentase yang digunakan untuk menilai sejauh mana perusahaan mampu menghasilkan laba pada tingkat yang dapat diterima. angka profitabilitas dinyatakan antara lain dalam angka laba sebelum atau sesudah pajak, laba investasi, pendapatan per saham, dan laba penjualan. Nilai profitabilitas menjadi norma ukuran bagi kesehatan perusahaan. Return on Asset adalah rasio yang menggambarkan return dari total aktiva perusahaan.

\section{ROA $=\underline{\text { Laba setelah bunga dan pajak }}$ Total Aktiva}

\section{PENGEMBANGAN HIPOTESIS}

\section{Pengaruh DER Terhadap Company Value}

Kebijakan pengambilan keputusan pendanaan melalui capital structure yang secara sungguhsungguh agar menjadi perhatian bagi perusahaan, oleh sebab itu struktur penentuan perusahaan akan berpengaruh terhadap company value (Meythi, 2012). capital structure menggambarkan perbandingan antara total utang jangka panjang dan modal sendiri. Perusahaan menggunakan hutang dalam kegiatan operasionalnya untuk mendapatkan penghematan pajak, penghematan pajak dapat dihitung melalui net income operasi dikurangi dengan hutang bunga, sehingga net income menjadi hak pemegang saham menjadi lebih besar dibanding dengan perusahaan yang tidak memakai utang. Dengan demikian nilai perusahaan menjadi lebih besar. Ini menunjukkan semakin besar capitalstructure maka company value menjadi meningkat lebih tinggi. Namun perusahaan mustahil memakai $100 \%$ hutang pada capital structure. Hal tersebut menyebabkan risiko keuangan perusahaan akan berubah menjadi besar ketika hutang semakin meningkat. Pertimbangan capital structure antara capitalasset dengan modal sendiri. Capital structure maksimum merupakan capital structure yang memaksimalkan balance antara risk and return sehingga memaksimalkan price stock. Hasil penelitianyang dilakukan oleh Heven dan Arie (2016) capital structure memiliki pengaruh positif dan signifikanterhadap company value.

\section{H1 : Capital structure berpengaruh negatif signifikan terhadap company value.}

\section{Pengaruh Size Terhadap Company Value}

Size yang diteliti adalah gambaran besar kecilnya perusahaan yang terlihat dari total nilai aktiva perusahaan. Semakin besar size perusahaan, maka ada kecenderungan investor tertarik menanamkan dananya pada perusahaan semakin besar. Ini dapat disebabkan akibat perusahaan memiliki tingkat stabilitas yang tinggi. Dengan tingkat kestabilan yang tinggi mengakibatkan investor tertarik untuk menanamkan sahamnya pada perusahaan. Investor memiliki harapan besar untuk memperoleh dividenyang besar dari perusahaan. Permintaan saham perusahaan yang meningkat mampu memacu peningkatan harga saham di pasar sekuritas (Showfatul, 2011). Besar kecilnya Size perusahaan dapat dilihat dari nilai ekuitas, yang merupakan nilai perusahaan (total aktiva yang dimiliki oleh perusahaan).

\section{H2 : Size berpengaruh positif terhadap Company Value.}

\section{Pengaruh Profitability Terhadap Company Value}

Jika manajemen ingin memaksimalkan nilai perusahaan, maka harus mengambil keuntungan dari kekuatan-kekuatan perusahaan dan memperbaiki kelemahan-kelemahannya. analisis laporan keuangan akan melibatkan membandingkan kinerja perusahaan dengan kinerja perusahaan-perusahaanlain dalam industri yang sama dan mengevaluasi tren posisi keuangan dari waktu ke waktu. Studi-studiini akan membantu manajemen mengidentifikasikan berbagai kekurangan yang mereka miliki dan kemudian mengambil tindakan untuk meningkatkan kinerjanya (Brigham \& Ehrhard, 2009). Rasio profitabilitas atau rasio rentabilitas menunjukkan keberhasilan perusahaan dalam menghasilkan keuntungan. Dalam penelitian ini profitabilitas diukur dengan return on Asset merupakan rasio yang sangatpenting bagi pemilik perusahaan (the common stakeholder). Karena rasio ini menujukkan tingkat kembalian yang dihasilkan oleh 
manajemen dari modal yang disediakan oleh pemilik saham. Semakintinggi nilai profit yang didapat maka akan semakin tinggi nilai perusahaan. Karena profit yang tinggi akan memberikan indikasi prospek perusahaan yang baik sehingga dapat memicu investor untuk meningkatkan permintaan saham. Permintaan saham yang meningkat akan menyebabkan nilai perusahaan yang meningkat.

H3 : Pengaruh Profitability berpengaruh positif signifikan terhadap Company Value.

\section{Conseptual Framework}

\section{Gambar 1. Conseptual Framework}

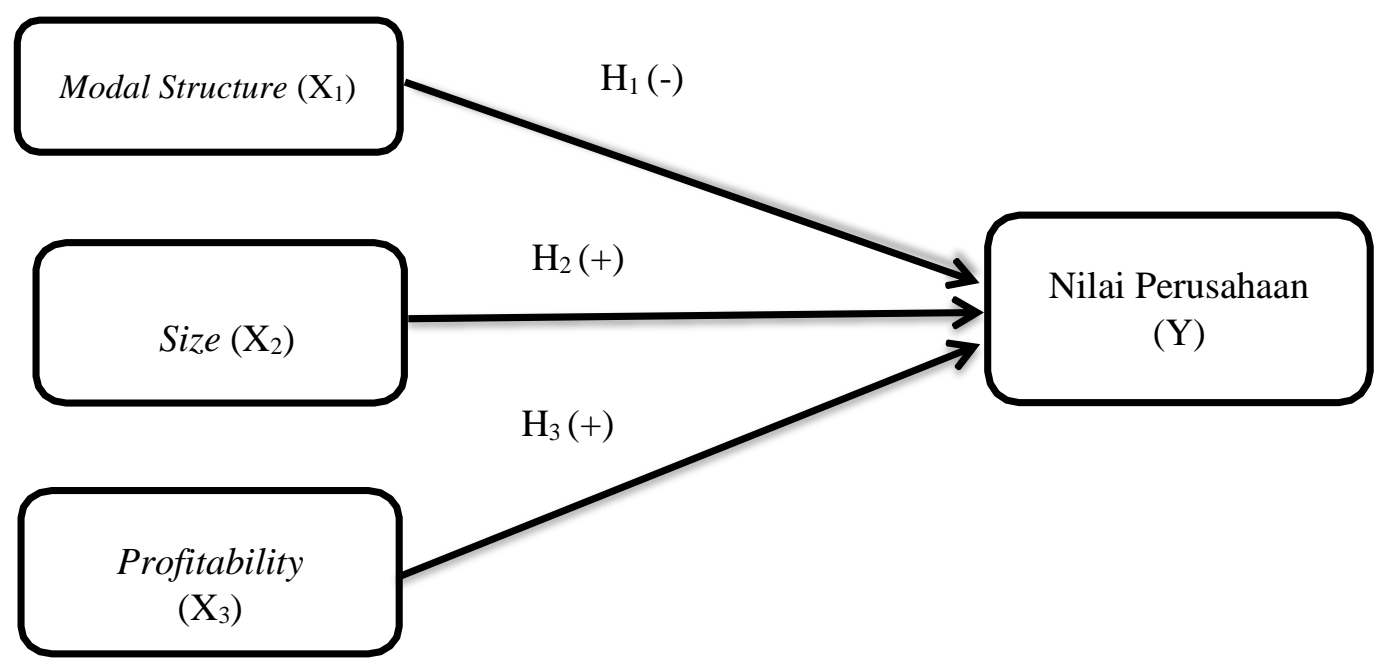

\section{METODE PENELITIAN}

Konsep penelitian mengadopsi metode penelitian kuantitatif. Penelitian kuantitatif adalah metode penelitian yang berdasarkan pada paham positivisme, untuk melakukan penelitian dengan populasi/sampel tertentu, penggunaan teknik pengambilan sampel secara acak, penggunaan isntrumen penelitian dalam pengumpulan data dan penggunaan analisis data secara kuantitatif/statistik untuk menguji hipotesis (Sugiyono, 2017). Penelitian mengambil populasi berupa 15 perusahaan otomotif yang ada pada list BEI periode tahun 2014-2018. Pengambilan sampel merupakan pengambilan beberapa bagian dari populasi dengan syarat tertentu (Sugiyono, 2017). Penelitian menggunakan teknik purposive sampling atau sampel bertujuan, yaitu pengambilan sampel yang dilakukan dengan cara mengambil subyek bukan didasarkan atas strata, acak atau daerah tetapi didasarkan atas tujuan tertentu.

Tabel.1 Kriteria Pengambilan Sampel

\begin{tabular}{clc}
\hline No & \multicolumn{1}{c}{ Kriteria } & Jumlah \\
\hline $\mathbf{1}$ & $\begin{array}{l}\text { Perusahaan Sub Bidang otomotif pada BEI periode rentang tahun } \\
2014-2018\end{array}$ & 15 \\
\hline $\mathbf{2}$ & $\begin{array}{l}\text { Perusahaan otomotif yang tidak mempunyai data laporan } \\
\text { keuangan yang lengkap guna penelitian }\end{array}$ & $(1)$ \\
\hline Jumlah & 14 \\
\hline
\end{tabular}




\section{HASIL DAN PEMBAHASAN}

\section{Ordinary Least Square}

\section{Tests of Normality}

Normalitas dilakukan dengan melakukan uji Jarque-Bera. Pengembalian keputusannya jika nilai prob. $J-B>$ Alpha 5\%, maka data akan memiliki distribusi yang normal. Berikut ini penjelasan tentang hasil pengolahan data yang menunjukkan data memiliki distribusi yang normal atau tidak.

Tabel 2.

Hasil Uji Normalitas tahap I

\begin{tabular}{ll}
\hline Jarque-Bera 163.3648 \\
\hline Probability 0 \\
\hline Sumber: data dioleh oleh eviews 10 (2021)
\end{tabular}

Tabel 2 memberikan gambaran bahwa hasil penelitian menunjukkan nilai residual persamaan regresi tidak berdistribusi normal. Hal ini terlihat dari J-B sebesar 163.3648 namun dengan prob $J-B$ 0.000000 yang lebih kecil dari Alpha 5\% (0.05) masalah data yang tidak berdistribusi normal dapat disembuhkan dengan tranformasi data dengan cara logaritma natural untuk menyamakan range data sehingga bisa menyamakan data.

Tabel 3.

Hasil Uji Normalitas tahap II

\begin{tabular}{ll}
\hline Jarque-Bera 133.5342 \\
\hline Probability 0 \\
\hline Sumber: data dioleh oleh eviews 10 (2021)
\end{tabular}

Tabel 3 menggambarkan bahwa nilai residual persamaan regresi pada penelitian ini berdistribusi tidak normal. Hal ini terlihat dari J-B sebesar 133.5342 namun dengan prob J-B 0.000000yang lebih kecil dari Alpha 5\% (0.05) masalah data tidak berdistribusi normal dapat disembuhkan dengan tranformasi data dengan cara logaritma natural pada variabel size karena untuk menyamakan range data. Setelah ditransformasi secara logaritma natural tidak berdistribusi normal sehingga dilakukan dengan scatter plot (mengurangi data yang outlier yang kemungkinan menghasilkan data yang tidak normal). Seluruh data yang didapat sebanyak 56 Observasi setelah di scatter plot didapat data sebanyak 35 observasi sehingga didalam penilitan ini mengurangi sebanyak 21 observasi. Kesimpulannya setelah discatter plot maka didapat data normalitas sebagai berikut:

Tabel 4.

Tabel Hasil Uji Normalitas Tahap III

\begin{tabular}{ll}
\hline Jarque-Bera & 0.103616 \\
\hline Probability & 0.949511 \\
\hline \multicolumn{2}{l}{ Sumber: Data diolah eviews $10(2021)$}
\end{tabular}

Tabel 4. menggambarkan bahwa nilai residual persamaan regresi pada penelitian ini memiliki nilai berdistribusi normal. Hal ini terlihat dari J-B sebesar 0.103616 namun dengan prob J-B 0.949511yang lebih besar dari Alpha 5\% (0.05).

\section{Uji Multikolinieritas}

Tabel 5.

Hasil Uji Multikolinieritas (koefisien korelasi)

\begin{tabular}{cccc}
\hline & DER & ROA & LOG_SIZE \\
\hline DER & 1 & 0.5454 & 0.5677 \\
\hline ROA & 0.5454 & 1 & 0.2318 \\
\hline LOG_SIZE & 0.5677 & 0.2318 & 1 \\
\hline
\end{tabular}

Sumber: data diolah eviews 10 (2021) 
Hasil uji korelasi antar variabel independen diatas tidak adanya nilai keeratan yang sangat tinggi 0.9 (> 90\%) antara variabel bebas. Variabel bebas saling terkait tetapi tidak lebih dari 0.9 (90\%) makadapat dikatakan tidak terjadi multikolinieritas.

\section{Uji Autokorelasi}

Tabel 6

Hasil Uji Autokorelasi

\begin{tabular}{lccc}
\hline F-Statistik & 0.3776 & Prob.F(2.29) & 0.6888 \\
\hline Obs*R-square & 0.888316 & Prob.Chi Square(2) & 0.6414
\end{tabular}

Sumber: Data diolah Eviews 10 (2021)

Hasil uji Breusch-Godfrey test menggambarkan prob. Chi-Square value sebesar $0.6414>0.05$, sehingga bisa dikatakan bahwa data tidak terdapat autokorelasi.

\section{Uji Heteroskedastisitas}

\section{Tabel 7.}

Hasil Uji Heteroskedastisitas

\begin{tabular}{llll}
\hline F-statistic & 1.620235 & Prob. F(3,35) & 0.2047 \\
\hline Obs*R-squared & 4.744042 & Prob. Chi-Square(3) & 0.1915 \\
\hline Scaled explained SS & 3.232473 & Prob. Chi-Square(3) & 0.3572 \\
\hline \multicolumn{4}{l}{ Sumber: data diolah Eviews 10 (2021) }
\end{tabular}

Pemeriksaan terhadap data menggambarkan gejala heteroskedastisitas terhadap Breusch- Godfrey (BPG) sehingga terlihat prob. Chi-Square value pada $O b s^{*} R$-Square sebesar $0.1915>0.05$, sehingga dapat terlihat tidak terjadi gejala heteroskedastisitas.

\section{Analisis Regresi Data Panel \\ Chow Test}

Uji chow digunakan dalam menilai common effect method atau fixed effect yang dipakai. Hasil pengambilan keputusan:

- Jika prob. Chi Square value $<0.05 \rightarrow$ pengaruh tetap

- Jika prob. Chi Square value $>0,05 \rightarrow$ pengaruh bersama

Tabel 8.

Chow Test

\begin{tabular}{lccc}
\hline Cross-section F & 3.675951 & -9.22 & 0.0061 \\
\hline $\begin{array}{l}\text { Cross-section } \\
\text { Chi-square }\end{array}$ & 32.12331 & 9 & 0.0002 \\
\hline
\end{tabular}

Sumber: data diolah Eviews 10 (2021)

Chow Tes menggambarkan prob. Chi-square value senilai 0.0002 , kurang dari alpha $5 \%$ $(0.0002<0.05)$ ini menunjukkan fixed effect yang dipilih.

\section{Hausman Test}

Hausman test dipakai untuk memilah apakah fixed effect atau random effect method yang digunakan. Pengambilan keputusan:

- Jika prob. Cross Section Random $<0.05 \rightarrow$ fixed effect

- Jika prob. Cross Section Random $>0.05 \rightarrow$ Random effect 
Tabel 9.

Hasil Uji Hausman

\begin{tabular}{lccc}
\hline Test Summary & $\begin{array}{c}\text { Chi-Sq. } \\
\text { Statistic }\end{array}$ & $\begin{array}{c}\text { Chi- } \\
\text { Sq. d.f }\end{array}$ & Prob. \\
\hline Cross-section random & 1.751018 & 3 & 0.6257 \\
\hline
\end{tabular}

Sumber: data diolah Eviews 10 (2021)

Hausman test menggambarkan prob. Cross section random value senilai $0.6257>0.05$, dapat disimpulkan bahwa model yang tepat digunakan adalah random effect models.

\section{Pemilihan model akhir}

Berdasarkan pengujian yang dilakukan, metode yang digunakan untuk mengestimasi model persamaan ini adalah metode random effect.

Tabel 10.

Uji Data Panel Random effect

\begin{tabular}{clcl}
\hline Variable & Coefficient & Prob. & R-squared \\
\cline { 1 - 3 } C & 4.727233 & 0.5566 & \\
\cline { 1 - 2 } DER? & 0.163066 & 0.6557 & \multirow{2}{*}{0.60602} \\
\cline { 1 - 2 } SIZE? & -0.644568 & 0.5929 & \\
\cline { 1 - 3 } ROA? & 0.074383 & 0.0851 & \\
\cline { 1 - 2 } & & &
\end{tabular}

Sumber: data diolah Eviews 10 (2021)

\section{Analisis Data Panel}

Berdasarkan tabel 4.9 dapat diketahui bahwa persamaan model estimasi adalah sebagai berikut:

$$
P B V=4.727233+0.163066 \text { DER }-0.644568 S I Z E+0.074383 R O A+\mathrm{e}
$$

Persamaan model regresi dapat dijelaskan:

1. constant senilai 4.727233, menggambarkan DER, SIZE, dan ROA dianggap memiliki nilai tetap, maka company value senilai 4.727233 .

2. Koef. regresi $D E R$ sebesar 0.163066 , menunjukkan jika $D E R$ naik sebanyak satu-satuan, maka company value naik senilai 0.163066 , sebaliknya jika $D E R$ turun sebanyak satusatuan, maka company value turun senilai 0.163066 .

3. Koefisien regresi SIZE sebesar -0.644568 menunjukkan jika SIZE naik sebanyak satusatuan, maka company value turun senilai 0.644568 , sebaliknya jika SIZE turun sebanyak satu-satuan, maka company value naik senilai 0.644568 .

4. Koefisien regresi $R O A$ sebesar 0.074383 artinya jika $R O A$ naik sebanyak satu-satuan, maka nilai perusahaan turun senilai 0.074383 . sebaliknya jika $R O A$ sebanyak turun satu-satuan, maka company value naik senilai 0.074383 .

\section{Pengujian Hipotesis}

Uji T

1. Variabel $D E R$ berpengaruh signifikan terhadap nilai perusahaan dari hasil ditabel diatas dapat disimpulkan tidak adanya pengaruh signifikan DER terhadap PBV, dibuktikan dengan nilai prob. $0.6557>0.05$, hal ini menggambarkan hipotesis tidak ada berpengaruh signifikan $D E R$ terhadap $P B V$.

2. Variabel Size berpengaruh signifikan terhadap nilai perusahaan dari hasil ditabel diatas dapat disimpulkan tidak adanya pengaruh signifikan Size terhadap $P B V$, dibuktikan dengan nilai prob. $0.5929>0.05$, hal ini menggambarkan hipotesis tidak berpengaruh signifikan Size terhadap $P B V$. 
3. Variabel ROA berpengaruh signifikan terhadap nilai perusahaan dari hasil ditabel diatas dapat disimpulkan tidak adanya pengaruh signifikan ROA terhadap PBV, dibuktikan dengan nilai prob. $0.0851>0.05$, hal ini menggambarkan hipotesis berpengaruh signifikan Return On Asset (ROA) terhadap Price Book Value (PBV).

\section{Koefisien Determinasi $\left(\mathbf{R}^{2}\right)$}

Koefiesiens determinasi $\left(\mathrm{R}^{2}\right)$ digunakan untuk mengukur seberapa jauh kemampuan model menerangkan variasi dari variabel independen. Berdasarkan tabel 4.8 diketahui R-squared sebesar 0.606020 atau $60.602 \%$. Dalam hal ini menunjukkan bahwa variabel independen Debt to Equity Ratio (DER), Size dan Return On Asset (ROA) dapat menejelaskan bahwa company value senilai $60.602 \%$, sedangkan sisanya $39.398 \%$, dijelaskan oleh variable lain, diluar variable penelitian ini.

\section{PEMBAHASAN}

$T$ test pertama menggambarkan bahwa modal structure tidak ada pengaruh signifikan terhadap company value pada perusahaan Otomotif yang terlist pada BEI periode tahun 2015-2018. Ini didukungoleh research finding dari Prasetia, Tommy dan Saerang (2014). Dengan demikian DER akan meningkatkan company value. Research finding mendukung modal structure theory yang menggambarkan tentang kondisi perusahaan yang harus mampu menyeimbangkan kegunaan dan beban yang diakibatkan oleh hutang sehingga tidak memunculkan masalah. Dengan demikian keuntungan akan meningkat ketika rasio DER semakin tinggi.

T test kedua menggambarkan tentang size tidak berpengaruh terhadap company value studi kasus pada perusahaan otomotif yang terlisting di BEI tahun 2015-2018. Hasil yang kedua cocok dengan penelitian Rahmawati (2015) dan Languju (2016) yang menghasilkan bahwa ukuran perusahaan tidak berpengaruh terhadap company value. Company value umumnya memiliki pengaruh pada penilaian investor dalam membuat keputusan memilih investasi. Size diukur dengan nilai jumlah asset yang dimiliki karena nilai jumlah asset biasanya memiliki nilai lebih besar dibandingkan dengan variabel keuangan yang lain. Size bukan menjadi pertimbangan bagi para investor dalam menanamkaninvestasi. Size yang besar belum tentu bisa menjamin company value menjadi lebih tinggi, hal ini disebabkan karena perusahaaan besar belum berani melakukan new investment terkait dengan perluasan usaha, sebelum kewajibankewajibannya telah di lunasi.

T test ketiga menggambarkan profitability dalam kesempatan ini diwakili oleh Return on Assettidak memiliki pengaruh terhadap company value studi kasus pada perusahaan Otomotif yang terlistingdi BEI tahun 2015-2018. Penelitian ini tidak memberikan bukti empiris bahwa company value juga akan naik jika ROA semakin meningkat, dengan demikian hasil ini bertolak belakang dengan teori yangada. Penelitian tersebut cocok dengan research finding dari penelitian Ain dan Setijaningsih (2012) yang menjelaskan bahwa Return on Asset tidak memiliki pengaruh terhadap company value.

\section{KESIMPULAN}

Penelitian diharapkan mampu memahami pengaruh capital structure, size dan profitability terhadap company value pada perusahaan yang bergerak di bidang otomotif yang terlisting pada BEI tahun 2015-2018. Variabel bebas yang dipakai adalah company value, kemudian variabel terikat yang dipakai adalah capital structure, size dan profitability.

1. Capital structure (Debt to Equity Ratio) tidak memiliki pengaruh terhadap company value pada perusahaan yang bergerak di bidang otomotif yang terlisting pada BEI tahun 2015-2018.

2. Size (Total Asset) tidak memiliki pengaruh terhadap company value pada perusahaan yang bergerak di bidang otomotif yang terlisting pada BEI tahun 2015-2018.

3. Profitability (Return on Asset) tidak memiliki pengaruh terhadap company value pada perusahaan yang bergerak di bidang otomotif yang terlisting pada BEI tahun 2015-2018. 
Jurnal Proaksi, Vol.8 (2), Hal. 303 - 312

\section{SARAN}

1. Saran Praktis : Bagi manajemen, capital structure harus kuat dan efisien agar perusahaan dapat bersaing dalam dunia kompetisi pasar ekuitas yang ketat. Perusahaan secara berkala harus mampu meningkatkan total aktiva sehingga struktur modal semakin meningkat, dengan stabilnya Capital Structure perusahaan akan memberi sinya positif bagi calon investor untuk datang dan Untuk para investor atau calon investor akan memberikan pilihan dan pemahamanterhadap kelayakan kondisi perusahaan.

2. Saran Teoritis : Untuk Penelitian di masa datang menyarankan untuk memperbanyak jumlah sampel dan jumlah tahun pengamatan untuk mendapatkan hasil penelitian yang lebih komprehensif.

\section{REFERENSI}

Ain, Syarifa dan Setijaningsih (2013). Pengaruh Return On Asset (ROA) Return On Equity (ROE) Dan Kepemilikan Manajerial Terhadap Nilai Perusahaan. Jurnal Akuntansi.

Brigham, Eugene F and Joel F. Houston, (2001). Manajemen Keuangan. Edisi Kedelapan Erlangga. Jakarta.

Brigham, Eugene F. dan Joel F. Houston, (2009). Dasar-dasar Manajemen Keuangan, Buku Satu, Edisi Kesepuluh, Alih Bahasa Ali Akbar Yulianto. Jakarta, Salemba Empat.

Brigham, Eugene F. dan Houston, Joel F., (2011). Dasar-dasar Manajemen Keuangan. Terjemahan. Edisi 10. Jakarta: Salemba Empat.

Harjito, Agus dan Martono, (2010). Manajemen Keuangan. Yogyakarta: Ekonisia.

Hartono, Jogiyanto, (2016). Teori Portofolio dan Analisis Investasi. Edisi. Kesepuluh. Yogyakarta.

Hevenmanoppo. Fitty Valdi Arie, (2016). Pengaruh Struktur Modal, Ukuran Perusahaan dan Profitabilitas Terhadap Nilai Perusahaan Otomotif yang terdaftar diBursa Efek Indonesia periode 2011-2014. Jurna EMBAl. ISSN:2303-1174 Vol.4 No.2.

Hidayati, E. Eko., (2010). Analisis Pengaruh DER, DPR, ROE dan Size terhadap PBV Perusahaan Manufaktur yang Listing di BEI Periode 2005-2007. Artikel. Universitas Diponegoro. http://eprints. undip.ac.id/24064/1/EVA_EKO_HIDAYATI-01.pdf. Diakses pada 16 Desember 2013. Hal. 1-14.

Husnan, Suad, (2001). Dasar-Dasar Teori Portofolio dan Analisis Sekuritas. Unit Penerbit danPercetakan AMP YKPN. BPFE, Yogyakarta.

Husnan, Suad, (2013). Manajemen Keuangan. Edisi Keempat. BPFE,Yogyakarta

I Nyoman Agus Suwardika dan I Ketut Mustanda, (2017). Pengaruh Leverage, Ukuran Perusahaan, Pertumbuhan Perusahaan dan Profitabilitas Terhadap Nilai Perusahaan Pada Perusahaan Properti. E-Jurnal Manajemen Unud, Vol. 6, No. 3, 2017: 1248-1277 ISSN : 2302-8912

Jensen, M. C. (2001). Value Maximization, Skateholder Theory, and The Corporate Objective Function. Working Paper, No. 01-09. Harvard Businnes School, PP. 1-21.

Kasmir. (2009). Pengantar Manajemen Keuangan. Kencana. Jakarta. Kasmir. (2009). Analisis Laporan Keuangan. Rajawali Pers, Jakarta.

Moniaga. (2013). Struktur Modal, Profitabilitas, dan Struktur Biaya Terhadap Nilai Perusahaan Industri Keramik, Porcelen dan Kaca periode 2007-2010. Jurnal EMBA 433 Vol.1 No.4 Desember 2013.

Prasetia, Ta'dir Eko, Parengkuan Tommy \& Ivon Saerang, (2014). Struktur Modal, Ukuran PerusahaanDan Risiko Perusahaan Terhadap Nilai Perusahaan Otomotif yang terdaftar di BEI. Jurnal EMBA 879 Vol.2 No.2 Juni 2014.

Riyanto, Bambang. (2008). Dasar-Dasar Pembelanjaan Perusahaan. Edisi Keempat. Yayasan Penerbit Gajah Mada, Yogyakarta. 
Jurnal Proaksi, Vol.8 (2), Hal. 303 - 312

Rumundor Regina, Maryam Mangantar dan Jacky Sumarauw, (2015). Pengaruh Struktur Modal, Ukuran Perusahaandan Risiko Perusahaan Terhadap Nilai Perusahaan pada Sub Sektor plastik dan pengemasan di BEI. Jurnal EMBA 159 Vol.3 No.3 Sept. 2015.

Saidi, (2004). Faktor-Faktor Yang Mempengaruhi Struktur Modal Pada Perusahaan Manufaktur Go- Public di BEI Tahun 1997-2002. Jurnal Bisnis dan Ekonomi, 11 (1): 44-58.

Shofwatul, Uyun, (2011). Pengaruh Manajemen Risiko, Ukuran Perusahaan dan Leverage terhadap Kinerja Keuangan Perusahaan pada Perusahaan Manufaktur yang Terdaftar di Bursa Efek Indonesia. Tesis, Universitas Airlangga.

Sugiyono, (2017). Metode Penelitian Kuantitatif, Kualitatif, dan R\&D. Bandung : Alfabeta. Syahyunan, (2013). Manajemen Keuangan: Perencanaan, Analisis, dan Pengendalian Keuangan.

Medan: USU Press

Ta'dir Eko Prasetia, Parengkuan Tommy dan Ivone S. Saerang, (2014). Struktur Modal, Ukuran Perusahaan, dan Risiko Perusahaan Terhadap Nilai Perusahaan Otomotif yang Terdaftar di BEI ISSN 2303-1174 Vol.2 No.2.

Wedari, Kusumaning, Linda. (2006). Analisis Pengaruh Proporsi Dewan Komisaris dan Keberadaan Komite Audit Terhadap Akuntansi Manajemen Laba. Simposium Nasional Akuntansi VII. 